\title{
GESTÃO POR COMPETÊNCIAS COM USO DA METODOLOGIA MULTICRITÉRIO NA AVALIAÇÃO DE PROFISSIONAIS DE APOIO ADMINISTRATIVO DE UM CALL
} CENTER

\section{MANAGEMENT-BASED COMPETENCIES USING MULTIPLE CRITERIA METHODOLOGY IN THE EVALUATION OF ADMINISTRATIVE SUPPORT PROFESSIONALS IN A CALL CENTER}

\footnotetext{
Maria do Céu de Sena Moura

Mestranda em Administração e Desenvolvimento Rural pela Universidade Federal Rural de Pernambuco - UFRPE.

Professora do Curso de Graduação em Processos Gerenciais da Universidade Salgado de Oliveira Universo.

E-mail: msena1976@gmail.com (Brasil)

\section{Marcos Felipe Falcão Sobral}

Doutor em Engenharia de Produção pela Universidade Federal de Pernambuco - UFPE.

Professor Adjunto do Departamento de Administração da Universidade Federal Rural de Pernambuco - UFRPE.

E-mail: marcos_sobral@bol.com.br (Brasil)
} 


\section{GESTÃO POR COMPETÊNCIAS COM USO DA METODOLOGIA MULTICRITÉRIO NA AVALIAÇÃO DE PROFISSIONAIS DE APOIO ADMINISTRATIVO DE UM CALL CENTER}

\section{RESUMO}

A tecnologia da informação fez algumas profissões sofrerem transformações estruturais. Novos cenários impulsionaram os secretários executivos a passar por constantes atualizações, ocasionando a inserção dos profissionais de Secretariado em diferentes contextos empresariais. O presente estudo foi realizado por um profissional de Secretariado Executivo e teve por objetivo classificar e analisar as competências: Conhecimento, Habilidade e Atitude (CHA). A avaliação por competências tem sido um instrumento bem-sucedido no julgamento do capital humano nas organizações. A classificação, à luz da gestão por competências, foi realizada através do Apoio Multicritério à Decisão, utilizando o método francês ELECTRE TRI. Na modelagem, os eixos do CHA foram inseridos no algoritmo como critérios e os profissionais avaliados foram tratados como alternativas. A pesquisa de campo de caráter exploratório foi direcionada a dez profissionais assessores administrativos que atuam num Call Center de Pernambuco. O embasamento teórico permitiu explorar a gestão por competências: Competências do profissional de Secretariado, a evolução do Call Center, Apoio Multicritério à Decisão e o ELECTRE TRI. A escolha do Call Center para a realização do estudo ocorreu por possuir em sua estrutura áreas de apoio em que os profissionais atuam, realizando trabalhos correlatos com a atividade de Secretariado. Os resultados mostraram que é possível realizar modelagens para cada tipo de função numa organização. Foi constatado que 50\% dos profissionais do grupo deste estudo foram classificados com baixo desempenho nas competências e $50 \%$ com competência elevada, resultado que se justifica, quando estratificamos o tempo de atividade dos profissionais.

Palavras-chave: Avaliação por Competências; Competências do Profissional de Secretariado Executivo; Call Center; Apoio Multicritério à Decisão; ELECTRE TRI.

Revista de Gestão e Secretariado - GeSec, São Paulo, v. 5, n. 3, p 01-27, set./dez. 2014. 


\title{
MANAGEMENT-BASED COMPETENCIES USING MULTIPLE CRITERIA METHODOLOGY IN THE EVALUATION OF ADMINISTRATIVE SUPPORT PROFESSIONALS IN A CALL CENTER
}

\begin{abstract}
Information technology has prompted certain professions to undergo structural transformations. New scenarios have driven executive secretaries to keep their careers updated and in turn exposing them to different business contexts. This study, conducted by a professional Executive Secretary, aimed to classify and analyze skills, more specifically the Knowledge, Skills and Attitude (KSAs). The assessment of competencies has been a successful tool in the judgment of human capital in organizations. As management-based competence is the focus, classification was performed through Multi-Criteria Decision Aid, using the French method ELECTRE TRI. In our model, the axes of the KSA were inserted in the algorithm as the criteria and the evaluated professionals were treated as alternatives. The exploratory field research was directed to ten professional administrative advisors working in a Call Center in Pernambuco, Brazil. The theoretical framework allowed exploring the following management competencies: Executive Secretariat Competencies, the evolution of the Call Center, Multi-Criteria Decision Aid and ELECTRE TRI. The Call Center used in this study was chosen based on having an administrative support structure in which professionals conduct work correlated to the activity of that from the Secretarial work. The results show that it is possible to perform modeling for each type of function in an organization. The study found that $50 \%$ of the professionals were classified as having low performance skills and 50\% with high competence, a result that is justified when the professionals activity time in the company is stratified.
\end{abstract}

Keywords: Competence Evaluation; Executive Secretariat Competencies; Call Center; Multicriteria Decision Aid; ELECTRE TRI.

Revista de Gestão e Secretariado - GeSec, São Paulo, v. 5, n. 3, p 01-27, set./dez. 2014. 


\section{INTRODUÇÃO}

O conceito de competência é baseado em três dimensões: Conhecimento, Habilidade e Atitude (CHA). Desta maneira, o Conhecimento está associado aos conjuntos estruturados de informações assimiladas pelo indivíduo, é o saber o que e por que fazer. A Habilidade é o saber como fazer. E a Atitude está relacionada aos aspectos comportamentais ao querer fazer. Essas três dimensões estão inter-relacionadas e são interdependentes; uma é ineficaz sem a outra (Durand, 2000). Nesse contexto, é possível afirmar que Competência é tomar iniciativa, assumir responsabilidade diante de situações profissionais com as quais se depara (Zarifian, 2012).

A tecnologia da informação fez algumas profissões sofrerem transformações estruturais, impulsionando os secretários executivos a passar por uma atualização e desenvolvimento profissional. Algumas atividades operacionais foram gradativamente substituídas por demandas mais estratégicas, como gestão da informação e liderança de equipes; por isso é crescente a inserção do profissional de Secretariado nos diversos setores da economia (Leal \& Fiates, 2013).

A escolha do Call Center para a realização do estudo ocorreu por ser um setor que possui áreas de apoio, ou áreas-meio em sua estrutura organizacional, com profissionais que atuam, realizando atividades correlatas com as de Secretariado: planejamento e controles internos, assistência e assessoramento direto a executivos, coleta de informações para a consecução de objetivos e metas da empresa, redação de textos profissionais especializados, inclusive em idioma estrangeiro para os Call Centers que atuam como offshore (atendimento a empresas estrangeiras no Brasil), palestras, registro e distribuição de expedientes, dentre outras tarefas afins. Além disso, este setor vem apresentando elevados índices de crescimento nas últimas décadas.

O objetivo deste estudo consistiu em analisar e classificar os funcionários que atuam como apoio administrativo de um Call Center, com base na gestão por competências. Foi utilizado o Modelo Multicritério de Apoio à Decisão, através do método ELECTRE TRI. Além da pesquisa de campo, de caráter exploratório, também foi realizada uma breve revisão de literatura, abordando as bases conceituais sobre Avaliação por competências: Competências do profissional de Secretariado Executivo, Call Center, Apoio Multicritério à Decisão e ELECTRE TRI.

A pesquisa de campo de caráter exploratório foi realizada por um profissional de Secretariado Executivo, com aplicação de questionários a dez profissionais que atuam como apoio administrativo de um Call Center do estado de Pernambuco. A amostragem corresponde a 90\% da equipe de staff da empresa. Tais profissionais atuam, realizando atividades correlatas às de Secretariado. A empresa estudada é especializada em recuperação de créditos e assessoria de Revista de Gestão e Secretariado - GeSec, São Paulo, v. 5, n. 3, p 01-27, set./dez. 2014. 
cobrança com operações de Call Center.

O método ELECTRE TRI teve origem na França e apresenta possibilidades de análises em diversos contextos empresariais. Considera pseudocritérios, usando limiares de indiferença e preferência, e cria uma relação de sobreclassificação valorada, ou seja, são atribuídos valores às alternativas. Este método tem sido aplicado em diversos contextos empresariais: no marketing, agronegócios, estudos em aeroportos, recursos humanos etc. (Almeida, 2013). É indicado em situações cuja problemática seja de classificação. Dessa maneira, permite que as alternativas sejam alocadas em classes, considerando os critérios importantes do problema, conforme a visão do decisor (Sobral, M. F., 2013).

O resultado do ELECTRE TRI demonstrou que 50\% dos profissionais foram classificados com baixo desempenho nas competências. Os outros 50\% apresentaram grau de competência elevada, resultado possivelmente justificado pelo tempo de atividade dos profissionais, visto que cerca de $30 \%$ deles possuem de um a seis meses na função. A modelagem surge como uma importante ferramenta de avaliação. Fornece ao decisor suporte nos processos de análises processuais, mapeamento de competências e auxilia nos processos de demissão, contratação e treinamentos.

\section{REFERENCIAL TEÓRICO}

\subsection{O CONCEITO DE COMPETÊNCIA}

Competência é uma palavra do senso comum, utilizada para designar pessoa qualificada para realizar algo (Fleury \& Fleury, 2011). No mundo do trabalho, a palavra competência vem assumindo diversos significados, alguns mais ligados às características da pessoa: Conhecimentos, Habilidades e Atitudes (McLagan, 1997). A competência é uma característica subjacente a uma pessoa que pode ser relacionada com desempenho superior na realização de uma tarefa. Ainda diferenciava competência de aptidões, o que seria um talento natural da pessoa (McClelland, 1973).

A literatura credita a David C. McClelland, 1973, a introdução do termo competência no contexto organizacional. Durante a década de 1980, Richard Boyatzis identificou um conjunto de características e traços que, segundo o autor, definem um desempenho superior (Boyatzis, 1992). Prahalad e Hamel (1990) deram um status estratégico ao tema, diferenciando competências

Revista de Gestão e Secretariado - GeSec, São Paulo, v. 5, n. 3, p 01-27, set./dez. 2014. 
organizacionais e competências essenciais. Competências organizacionais seriam a capacidade de combinar, misturar e integrar recursos em produtos e serviços.

Dessa maneira, as competências essenciais seriam aquelas que são regidas por três critérios: oferecem benefícios aos consumidores, são difíceis de imitar e abrem acesso a diferentes mercados, ou seja, ao definir sua estratégia competitiva, a empresa define as competências do negócio e as necessárias a cada função (Fleury \& Fleury, 2011).

Durand (2000) construiu um conceito de competência baseado em três dimensões: Conhecimento, Habilidade e Atitude (CHA). O eixo das competências engloba não só as questões técnicas, mas também a cognição e as atitudes relacionadas ao trabalho.

O Conhecimento está associado aos conjuntos estruturados de informações assimiladas pelo indivíduo. É o saber o que e por que fazer (know-what e know-why). A Habilidade ou know-how é o saber como fazer. Relaciona-se à capacidade de agir concretamente de acordo com objetivos ou processos predefinidos. A Atitude está ligada aos aspectos comportamentais, ao querer fazer. Essas três dimensões estão inter-relacionadas e são interdependentes, uma é ineficaz sem a outra (Durand, 2000). A Figura 1 demonstra as três dimensões da competência.

Figura 1 - As três dimensões da competência.

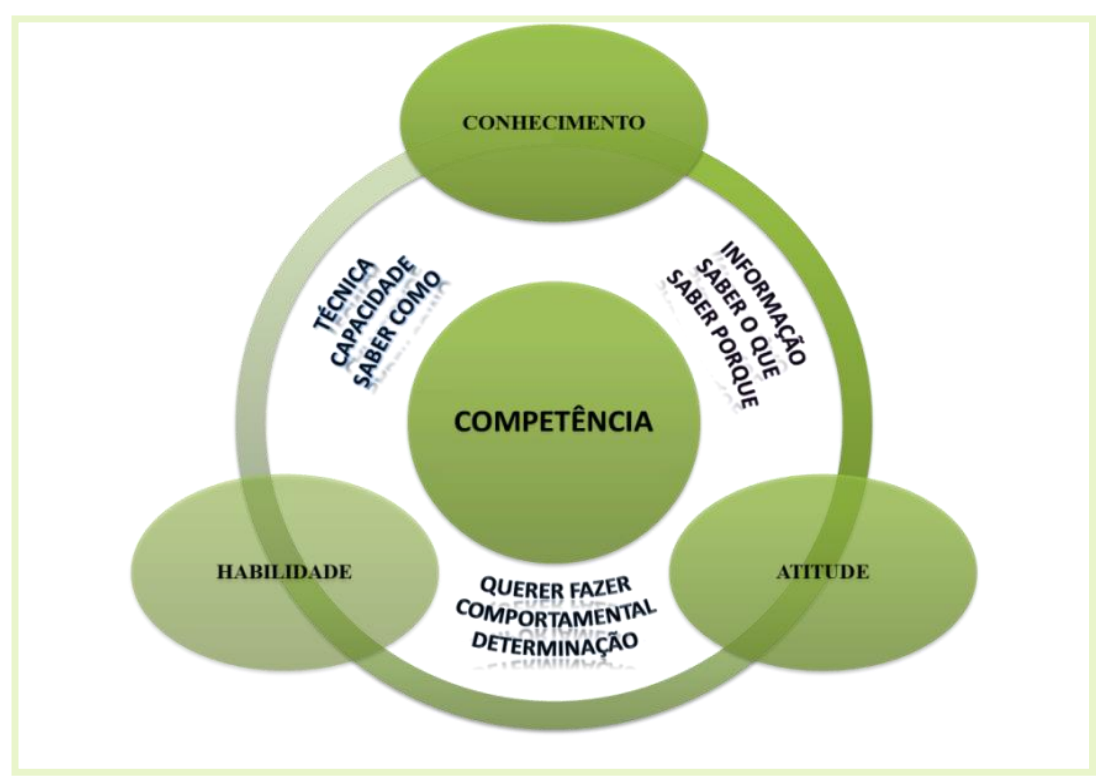

Fonte: Adaptado de Durand (2000).

O modelo de avaliação por competência tem sido aplicado em estudos gerenciais de diferentes áreas, sob a ótica do profissional de Secretariado Executivo, uma vez que ele, além de Revista de Gestão e Secretariado - GeSec, São Paulo, v. 5, n. 3, p 01-27, set./dez. 2014. 
executar as atividades técnicas inerentes ao cargo, também atua na gestão empresarial (Barros, Silva, Lima, \& Brito, 2013). O modelo de avaliação é empregado também na noção de competências no marketing, na relação comprador fornecedor (Golfetto \& Gibbert, 2006), em organizações bancárias (Bahry \& Tolfo, 2004), em estudo acerca da inserção das competências em cursos de graduação em Administração, visando contribuir com as reflexões sobre formação de competências (Nunes \& Barbosa, 2009).

Zarifian (2012) diferencia as competências em uma organização, estabelecendo competências em processos, sobrepondo as competências em ferramentas; técnicas e desempenho mais do que as evoluções tecnológicas; competência social e a do saber ser. Diante da abordagem do saber ser, supõe-se que o comportamento é adquirido e pode evoluir, ainda que em condições de avaliação. Não é o "ser" que se procura apreender, mas o modelo de conduta, diante de determinado ambiente.

\subsection{AS COMPETÊNCIAS DO PROFISSIONAL DE SECRETARIADO EXECUTIVO}

A profissão de Secretariado Executivo foi formalizada por meio da Lei n. 7.377, de 30 de setembro de 1985 (complementada pela Lei n. 9.261, de 10 de janeiro de 1996). Este decreto estabeleceu como pré-requisito para o seu exercício a diplomação em curso superior de Secretariado ou em curso superior de quaisquer áreas afins do conhecimento.

Delimitou, ainda, as seguintes competências da profissão em dez áreas essenciais: planejamento, organização e direção de serviços de secretaria; assistência e assessoramento direto a executivos; coleta de informações para a consecução de objetivos e metas de empresas; redação de textos profissionais especializados, inclusive em idioma estrangeiro; interpretação e sintetização de textos e documentos; taquigrafia de ditados, discursos, conferências, palestras de explanações, inclusive em idioma estrangeiro; versão e tradução em idioma estrangeiro, para atender às necessidades de comunicação da empresa; registro e distribuição de expedientes e outras tarefas correlatas; orientação da avaliação e seleção da correspondência para fins de encaminhamento à chefia; e conhecimentos protocolares (planalto.gov.br, 2014).

$\mathrm{O}$ advento da tecnologia da informação reduziu significativamente o tempo exigido para a execução das tarefas, associadas ao elevado nível de complexidade a que as organizações foram submetidas, permitindo uma série de responsabilidades, além das descritas nas leis de

Revista de Gestão e Secretariado - GeSec, São Paulo, v. 5, n. 3, p 01-27, set./dez. 2014. 
regulamentação (Moreira \& Olivo, 2012). Tal cenário impulsionou os secretários executivos a passar por uma atualização e desenvolvimento profissional. Atividades operacionais, como datilografia, taquigrafia de ditados e registro e distribuição de expedientes foram gradativamente substituídas por demandas mais estratégicas, como gestão da informação e liderança de equipes (Leal \& Fiates, 2013).

Essas novas competências permitiram que esses profissionais ocupassem um espaço significativo junto aos gestores, ao mesmo tempo em que viabilizaram o desenvolvimento de um maior nível de autonomia. Passaram a participar dos processos decisórios, a identificar dificuldades e solucioná-las, analisar e interpretar informações, trabalhar em equipe e atuar como agentes de mudanças nas organizações em diversos setores da economia (Leal \& Fiates, 2013). Alguns estudos sobre as competências dos secretários executivos são destacados no Quadro 1.

\begin{tabular}{|c|l|}
\hline AUTORES & \multicolumn{1}{|c|}{ RESUMO DO ESTUDO } \\
\hline $\begin{array}{c}\text { Pereira \& Silva, } \\
\text { 2014) }\end{array}$ & $\begin{array}{l}\text { O estudo revelou a atuação do secretário executivo no terceiro setor na cidade de } \\
\text { Aracaju. Foi identificado, no que se refere ao perfil dos secretários, que a maioria } \\
\text { não possui formação específica. São polivalentes e não são inovadores. }\end{array}$ \\
\hline $\begin{array}{c}\text { (Lima \& Cantarotti, } \\
\text { 2010) }\end{array}$ & $\begin{array}{l}\text { Os autores abordam a formação e a construção de competências para a atuação do } \\
\text { profissional de Secretariado Executivo. Um estudo de caso em uma empresa } \\
\text { júnior. }\end{array}$ \\
\hline $\begin{array}{c}\text { Todorov, Kniess, \& } \\
\text { Chaves, 2013) }\end{array}$ & $\begin{array}{l}\text { Este estudo se propôs a identificar as competências do profissional de Secretariado } \\
\text { na implantação de projetos sustentáveis, pesquisando em quais projetos } \\
\text { sustentáveis o profissional de Secretariado está inserido, e analisando seu } \\
\text { envolvimento nesses projetos. }\end{array}$ \\
\hline $\begin{array}{c}\text { (Barros, Silva, Lima, } \\
\text { \& Brito, 2013) }\end{array}$ & $\begin{array}{l}\text { Este trabalho consiste em identificar as competências gerenciais desenvolvidas por } \\
\text { uma amostra de secretários executivos no exercício da profissão. }\end{array}$ \\
\hline
\end{tabular}

Quadro 1 - Estudos sobre as competências dos profissionais de Secretariado Executivo.

Fonte: Elaborado pelo autor (2014).

Com base nos artigos revisados, os estudos realizados sobre as competências dos profissionais de Secretariado reforçam a importância deles e a sua inserção nos diversos segmentos do mercado de trabalho. Ainda, nos estudos de Almeida, Rogel e Shimoura (2010) sobre as mudanças de paradigmas na gestão do profissional de Secretariado, percebeu-se que este profissional tem uma visão global do negócio da empresa em que trabalha e com isso mantém um relacionamento produtivo com os clientes internos e externos (Almeida, Rogel, \& Shimoura, 2010). É possível, sobretudo, entender o profissional de Secretariado Executivo como coparticipante na gestão de processos e responsável por contribuir nas tomadas de decisão da organização (Mascarenhas, Sepulveda, \& D’Assumpção, 2011).

Revista de Gestão e Secretariado - GeSec, São Paulo, v. 5, n. 3, p 01-27, set./dez. 2014. 


\subsection{A EVOLUÇÃO DO CALL CENTER}

O atendimento ao consumidor por telefone começou em Berlim, em 1880, logo após Alexander Graham Bell patentear o primeiro telefone na Inglaterra. Um pasteleiro que possuía um cadastro de clientes, ainda que rudimentar, oferecia seus produtos à clientela, por telefone (Jamil \& Silva, 2005).

A internet e a tecnologia de informação e comunicação fizeram com que as empresas se conectassem aos seus clientes, distribuidores, fornecedores e colaboradores, criando redes de relacionamento (Maximiano, 2012). Ainda nesse contexto, existem várias soluções de software e de telefonia integradas ao computador, que auxiliam o call center a trabalhar com maior produtividade, dentre elas: a discagem preditiva (Predictive Dialing); sistemas de gerenciamento de performance, monitoração de qualidade, gerenciamento do relacionamento com o cliente. Customer Relationship Management (CRM); Unidades de Resposta Audível (URA); Distribuidor Automático de Chamadas (DAC); Integração Telefone-Computador (CTI); e Voz sobre IP (VoIP) (Jamil \& Silva, 2005).

O termo Call Center pode ser conceituado da seguinte forma:

- Call: fazer uma requisição ou chamada;

- Center: área ou um ponto onde se desenvolvem atividades com objetivos determinados.

No passado, havia uma definição que descrevia o call center como uma central de negócios por telefone, combinando um banco de dados com um sistema de distribuição de chamadas. Este conceito, porém, vem sofrendo mudanças, ao passo que as empresas percebem que para atrair e manter clientes é preciso oferecer um elevado portfólio de serviços (Madruga, 2009b).

O call center possui dois decretos nacionais, que regem o setor: o decreto 6.523, em vigor desde $1^{\circ}$ de dezembro de 2008, que regulamenta a Lei n. 8.078, de 11 de setembro de 1990. O decreto foi criado para atender a uma demanda da sociedade e regulamentar o serviço de SAC (planalto.gov.br, 2014); e o anexo II da NR 17 da Portaria n. 9, de 30 de março de 2007, foi marco regulatório para o setor de teleatendimento/telemarketing, normatizando assuntos relacionados à segurança e saúde no trabalho dos profissionais que atuam na área (portal.mte.gov.br/, 2014).

Existem também algumas normas que caminham em conjunto com a legislação brasileira.

Revista de Gestão e Secretariado - GeSec, São Paulo, v. 5, n. 3, p 01-27, set./dez. 2014. 
Em 2005, a Associação Brasileira de Marketing Direto (ABEMD), a Associação Brasileira das Relações Empresa Cliente (Abrarec) e a Associação Brasileira de Telesserviços (ABT) lançaram o Código de Ética do Programa Brasileiro de Auto-Regulamentação do Setor de Relacionamento (Probare) (Madruga, 2009a).

O Código de Ética Probare é aplicável às Centrais de Relacionamento, também chamadas de Call Center, Contact Center, Help Desk, Serviço de Atendimento ao Consumidor (SAC) e/ou Telemarketing, próprias ou terceirizadas, que executam atividades de atendimento ativo e/ou receptivo, para Consumidores (pessoas físicas e jurídicas), por meio de telefone, e-mail, chat, fax, cartas para, dentre outros, os seguintes serviços (ABT, 2014).

A Tabela 1 traz uma radiografia do faturamento das empresas brasileiras de Call Center.

Tabela 1 - Radiografia do mercado brasileiro de Call Center.

\begin{tabular}{|c|c|c|c|c|c|}
\hline Ano & $\begin{array}{c}\text { Faturamento } \\
\text { bruto } \\
\text { (R\$ milhões) }\end{array}$ & $\begin{array}{c}\text { Posições } \\
\text { de atendimento } \\
\text { (PAs) }\end{array}$ & $\begin{array}{c}\text { Faturamento } \\
\text { médio por P.A } \\
\text { (R\$ mil) }\end{array}$ & $\begin{array}{c}\text { Número } \\
\text { de } \\
\text { Funcionários }\end{array}$ & $\begin{array}{c}\text { Fat. médio por } \\
\text { funcionário } \\
\text { (R\$ mil) }\end{array}$ \\
\hline 2008 & $6.418,2$ & 121.547 & 52,8 & 259.014 & 24,8 \\
\hline 2009 & $7.098,1$ & 127.809 & 55,5 & 266.738 & 26,6 \\
\hline 2010 & $8.287,2$ & 141.896 & 58,4 & 287.152 & 28,9 \\
\hline 2011 & $10.219,6$ & 158.543 & 64,4 & 308.473 & 33,1 \\
\hline 2012 & $8.351,1$ & 138.775 & 60,2 & 260.501 & 32,1 \\
\hline
\end{tabular}

Fonte: callcenter.inf.br (2014).

O site callcenter.inf.br. (2014) apresenta uma radiografia do mercado de Call Center brasileiro a partir das informações passadas pelas empresas. As informações da Tabela 1, portanto, representam apenas as empresas que publicaram seus dados de 2008 a 2012.

Uma pesquisa realizada pelo Centro de Inteligência Padrão (CIP), em 2013, indicou que no mercado brasileiro as demandas recebidas por telefone representam $80 \%$ do total dos contatos contra $1,28 \%$ das redes sociais, ou seja, apesar de as empresas de diversos setores da economia investirem nas redes sociais, o telefone ainda é escolhido no momento em que o consumidor quer uma solução imediata (CIP, 2013).

\subsection{A IMPORTÂNCIA DO PROFISSIONAL DE SECRETARIADO NA GESTÃO DE PESSOAS NO CALL CENTER}

A indústria do Call Center apesar de ser um mercado promissor, apresenta uma carência de profissionais especializados em apoiar e gerir as pessoas (Madruga, R., 2009b). Desta maneira, a

Revista de Gestão e Secretariado - GeSec, São Paulo, v. 5, n. 3, p 01-27, set./dez. 2014. 
inserção do profissional de Secretariado Executivo nos diversos setores do mercado de trabalho darse-á a partir de suas definições que o habilitam previamente como um profissional multidisciplinar capaz de exercer as funções como mediador de conflitos, de intermediar as relações do gestor com ambientes interno e externo, de organizar, empreender, assumir responsabilidades, além de participar dos processos decisórios com capacidade para solucionar problemas nos diferentes contextos empresariais (Moreira \& Olivo, 2012).

No ambiente empresarial de Call Center, o trabalho do atendente é carregado de estigmas negativos. É considerado um emprego passageiro, o ritmo é intenso, com poucas pausas de descanso, e com regras e normas que padronizam e enrijecem a conduta dos operadores com formas de controles difusas. Em algumas situações, eles são controlados pelos próprios pares. Tal pressão por produção dificulta a criação de vínculos de amizade e coesão nas equipes de trabalho (Ricci \& Rachid, 2013).

As mediações de conflitos, portanto, proporcionam um equilíbrio entre o prazer e o sofrimento no trabalho dos operadores. A hipótese de que os profissionais estão encontrando um meio de administrar os problemas da organização do trabalho parece se concretizar. Ao mesmo tempo em que alguns fatores causam desgastes gerados pela gestão taylorista, outros proporcionam prazer como, por exemplo, os fatores sociais, que possibilitam o reconhecimento (Scolari, Costa, \& Mazzilli, 2009).

Sabino e Marchelli (2009) apresentam o Secretariado como constituindo um campo interdisciplinar de conhecimentos, o qual se utiliza de várias ciências, tanto com respeito à formação, quanto à atuação profissional. O secretário executivo atua em apoio aos líderes empresariais nos processos administrativos, na gestão de pessoas. É uma função majoritariamente exercida por mulheres.

Os estudos de Terra e Machado (2011) mostram que o profissional de Secretariado valoriza a realização profissional, como motivação e sentido do trabalho; busca manter o clima organizacional agradável, através da capacidade de flexibilização; atribui muita importância ao diálogo, a fim de identificar as ameaças e oportunidades e manter a harmonia no ambiente de trabalho.

Ainda, nos estudos de Barros e colaboradores (2013), na visão dos profissionais entrevistados, as competências gerenciais são utilizadas no Secretariado Executivo nas suas diversas responsabilidades, contribuindo para o alcance de objetivos e metas organizacionais, através da

Revista de Gestão e Secretariado - GeSec, São Paulo, v. 5, n. 3, p 01-27, set./dez. 2014. 
participação no planejamento, na condução e estímulo às pessoas e no controle dos processos.

A profissão de Secretariado Executivo vem crescendo, ao mesmo tempo em que o desenvolvimento humano e tecnológico também sobressai - dois itens necessários nas organizações (Fontanella, 2011). Dessa forma, o profissional de Secretariado se mostra proativo, capaz de tomar decisões de forma mais assertiva, respaldado pela capacidade de liderança, gerindo de forma inteligente e ativa setores e pessoas dos mais diversos perfis, atuando entre os diferentes públicos envolvidos no processo administrativo (Adelino \& Silva, 2012).

Para tanto, as pessoas que formam o corpo funcional contribuem para a instalação de um clima organizacional favorável, que gera resultados. Seja nos negócios ou em qualquer atividade da empresa, o capital humano serve de combustível e faz a máquina (organização) andar e chegar ao caminho desejado (Araujo \& Garcia, 2010).

\subsection{APOIO À DECISÃO E O MÉTODO ELECTRE TRI}

No cotidiano das organizações, várias decisões são tomadas com ou sem o uso de métodos formais de apoio à decisão (Almeida A. T., 2013). Na medida em que aumenta a complexidade interna na empresa, o processo de decisão tende a se tornar também mais complexo (Oliveira, 2011). O apoio à decisão auxilia na obtenção de elementos que respondam às questões expostas por um decisor (stakeholder). Em um processo decisório, tais elementos trabalham para classificar a decisão, conduzindo-a a uma recomendação (Roy B., 1996).

A finalidade de adotar múltiplos critérios é ajudar a tomar melhores decisões. Dessa maneira, o Método Apoio Multicritério à Decisão (MCDA) permite aumentar o grau de conformidade e coerência entre a evolução de um processo de tomada de decisão e os sistemas de valores e objetivos dos envolvidos neste processo (Roy B., 1990).

O apoio à decisão surgiu em 1960 e desde então tem passado por processos de evolução. Como parte disto, houve o surgimento de várias escolas, dentre elas a americana e a europeia. A Escola Americana é constituída de estrutura axiomática, que agrega critérios em função-síntese, estabelecendo compensação entre estes, como se apresenta na teoria da utilidade Multiatributo (Sobral, M. F., 2013). Em contrapartida, a Escola Europeia segrega alternativas critério a critério, explorando conceitos de dominância e eficiência, através dos métodos de sobreclassificação (Roy \& Vanderpooten, 1996).

Roy (1996) e Gomes, Araya e Carignano (2004) categorizam os tipos de problemáticas existentes da seguinte forma:

Revista de Gestão e Secretariado - GeSec, São Paulo, v. 5, n. 3, p 01-27, set./dez. 2014. 
- Problemática tipo $\alpha$ (P. $\alpha)$ : selecionar a "melhor" alternativa ou as melhores alternativas;

- Problemática tipo $\beta$ (P.ß): realizar a classificação das alternativas, ou seja, acatar as alternativas que parecem "boas" e descartar as que parecem "ruins";

- Problemática tipo $\gamma($ P. $\gamma)$ : gerar uma ordenação das alternativas;

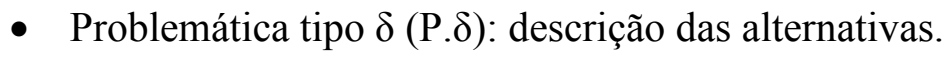

Essas problemáticas não são independentes entre si, uma vez que parece lógico pensar que a ordenação das alternativas $(\mathrm{P} \gamma)$ pode servir de referência ou de base para resolver problemas de seleção da melhor alternativa (P $\alpha)$ (Gomes, Araya, \& Carignano, 2004).

Dentre as abordagens alternativas para o estudo da classificação e ordenação de problemas, o método Multicritério de Apoio à Decisão (MCDA) fornece um arsenal de ferramentas e métodos para desenvolver classificação e modelos de classificação dentro de um contexto flexível e realista (Zopounidis \& Doumpos, 2002).

Assim, a construção do modelo de decisão que vai representar o estudo a ser realizado se utiliza de um método de apoio à decisão. A aplicação do MCDA evidencia a necessidade do estabelecimento dos objetivos que o decisor pretende alcançar, constituindo a representação destes múltiplos objetivos, através de múltiplos critérios ou múltiplos atributos (Almeida A. T., 2013).

Os métodos da família ELECTRE (Elimination et Choix Traduisant la Realité), pertencentes à Escola Europeia, foram desenvolvidos na França por Bernard Roy e associados na University of Paris Dauphine para auxílio à Decisão, e apresentam as seguintes subdivisões: ELECTRE I, II,III, IV e TRI (Roy, 1996).

O ELECTRE TRI é um método de sobreclassificação da família ELECTRE, proposto inicialmente por Yu (1992). Considera a problemática tipo $\beta$ (P. $\beta$ ), ou seja, classifica as diversas alternativas para a solução de um problema, por meio da comparação de cada alternativa potencial com uma referência estável (Roy, 1996; Yu, 1992).

São consideradas, portanto, as avaliações das alternativas para cada critério $\left\{g_{1}, \ldots, g_{i}, \ldots g_{m}\right\}$ e um conjunto de índice de perfis $\left\{b_{1}, \ldots, b_{i}, \ldots b_{m}\right\}$. Definem-se $p+1$ categorias, em que $b_{h}$ representa o limite superior da categoria $c_{h}$ e o limite inferior da $C_{h}+1$, onde $h=1,2, \ldots, p$ (Almeida A. T., 2013) .

O ELECTRE TRI trata de problemas que são modelados por uma família de pseudocritérios. Os limiares de preferência e indiferença, $p_{j}\left(b_{h}\right) e q_{j}\left(b_{h}\right)$, constituem as informações intracritérios. Assim, $q_{j}\left(b_{h}\right)$ especifica a maior diferença $g_{j}(a)-g_{j}\left(b_{h}\right)$, que preserva a indiferença entre a e $b_{h}$ no

Revista de Gestão e Secretariado - GeSec, São Paulo, v. 5, n. 3, p 01-27, set./dez. 2014. 
critério $g_{j}$, e $p_{j}\left(b_{h}\right)$. Representa a menor diferença $g_{j}(a)-g_{j}\left(b_{h}\right)$, compatível com uma preferência de a no critério $g_{j}$ (Szajubok, Mota, \& Almeida, 2006). Para construção do modelo, devem ser calculados os índices de concordância global e parcial, e o índice de discordância, conforme as equações.

$$
\begin{gathered}
c_{j}(a, b)= \begin{cases}0 \text { if } \quad g_{j}\left(b_{h}\right)-g_{j}(a) \geq p_{j}\left(b_{h}\right) \\
1 \text { if } \quad g_{j}\left(b_{h}\right)-g_{j}(a) \leq q_{j}\left(b_{h}\right) \\
\frac{p_{j}\left(b_{h}\right)+g_{j}(a)-g_{j}\left(b_{h}\right)}{p_{j}\left(b_{h}\right)-q_{j}\left(b_{h}\right)} n . c\end{cases} \\
c(a, b)=\frac{\sum_{j \in F} k_{j} c_{j}\left(a, b_{h}\right)}{\sum_{j \in F} k_{j}} \\
d_{j}(a, b)=\left\{\begin{array}{l}
1 \text { if } \quad \begin{array}{l}
g_{j}\left(b_{h}\right)-g_{j}(a)>v_{j}\left(b_{h}\right) \\
p_{j}\left(b_{h}\right)+g_{j}(a)-p_{j}\left(b_{h}\right) \\
v_{j}\left(b_{h}\right)-p_{j}\left(b_{h}\right)
\end{array} \quad n . c
\end{array}\right.
\end{gathered}
$$

Avaliando um problema de ordenação em que as alternativas têm de ser atribuídas a três categorias, $C_{1}$; $C_{2}$ e $C_{3}$, e definidas por dois perfis, $b_{1}$ e $b_{2}=(B=\{1,2\})$, tendo em vista as suas avaliações em três critérios, $g_{1}, g_{2}$ e $g_{3}(F=\{1 ; 2 ; 3\})$. As avaliações em cada critério devem atribuir valores no intervalo [0, 100] (Mousseau \& Slowinski, 1998).

O ELECTRE TRI oferece um processo de comparação entre as referências, sem que o forte desempenho de um critério sobreponha o de fraco desempenho, e consegue estabelecer uma classificação através da análise de múltiplos critérios (Sobral, M. F., 2013). Outra questão a ser considerada na modelagem do ELECTRE TRI é que se deve escolher entre os procedimentos pessimista e otimista (Mousseau \& Slowinski, 1998), na análise de sensibilidade. Quando os dois resultados pessimista e otimista se igualam, é possível afirmar que a classificação ocorreu de forma mais consistente (Sobral, M. F., 2013). 


\section{METODOLOGIA}

A metodologia consistiu em pesquisa de campo de caráter exploratório, que tem o propósito de proporcionar maior familiaridade com o problema, objetivando torná-lo mais explícito (Gil, 2010). Os dados foram submetidos às análises quantitativas. O método quantitativo reduz as amostras, sintetizando os dados de forma numérica, tabulando-os (Marconi \& Lakatos, 2011).

A coleta de dados foi realizada por um profissional de Secretariado Executivo, por meio da aplicação de questionários fechados. Foi elaborado e aplicado um Termo de Consentimento Livre e Esclarecido, processo formal de esclarecimento, informando a natureza da pesquisa e que o respondente pode ser livre para participar, declinar da participação ou deixar de responder a qualquer pergunta.

O questionário foi composto por duas partes: na primeira, as cinco questões iniciais foram direcionadas a mapear o perfil do respondente. Na segunda, as questões foram estruturadas com base nas três dimensões do modelo de avaliação por competências: Conhecimento, Habilidade e Atitude (CHA).

Cada item da pesquisa continha questões de múltipla escolha e de grau de domínio, utilizando uma escala Likert de 1 a 4, sendo o código de domínio 1 - ruim; 2 - razoável; 3 -bom; e 4 - excelente. Os questionários foram elaborados com base no modelo usado por Russo (2010) com algumas modificações: cada questão busca identificar a percepção dos profissionais sobre suas vivências no trabalho (Russo, 2010).

Os questionários foram aplicados em dez funcionários, $90 \%$ do quadro de profissionais que atuam nas áreas de apoio administrativo de uma operação de Call Center em Pernambuco. A quantidade de profissionais se justifica por se tratar de uma empresa de pequeno porte.

Para apoiar a operação do Call Center, os profissionais atuam na execução de rotinas administrativas e de gestão, executando atividades de administração de recursos humanos (gestão de pessoal, seleção, treinamento, desenvolvimento e contratações), gestão de clientes (nas atividades de envio de correspondências e boletos bancários), gestão da qualidade (na monitoração de ligações com práticas de avaliações e feedback), gestão financeira e gestão de pessoas.

O perfil do grupo de profissionais apresenta as seguintes características: $70 \%$ dos cargos são ocupados majoritariamente por mulheres; $40 \%$ têm idade entre 22 e 25 anos e $40 \%$, entre 26 e 31 anos; $40 \%$ estão executando a atividade entre um e dois anos e 30\%, entre um e seis meses, $20 \%$

Revista de Gestão e Secretariado - GeSec, São Paulo, v. 5, n. 3, p 01-27, set./dez. 2014. 
acima de quatro anos e $10 \%$ entre dois e três anos; $50 \%$ possuem nível superior completo e $30 \%$ têm superior incompleto.

Para a modelagem do ELECTRE TRI, os eixos do CHA foram inseridos no algoritmo como critérios, enquanto que os funcionários avaliados foram tratados como alternativas. Os pesos dos critérios foram atribuídos de acordo com a necessidade de desenvolvimento das competências para assessores administrativos definidos pelo decisor, o diretor-geral da empresa.

A classificação e a análise dos dados dos funcionários foram realizadas com base na avaliação por competências, através do uso da abordagem de Apoio Multicritério à Decisão (MCDA), utilizando o ELECTRE TRI. A Figura 2 demonstra as etapas de realização do estudo.

Figura 2 - Fluxograma etapas de realização do estudo.

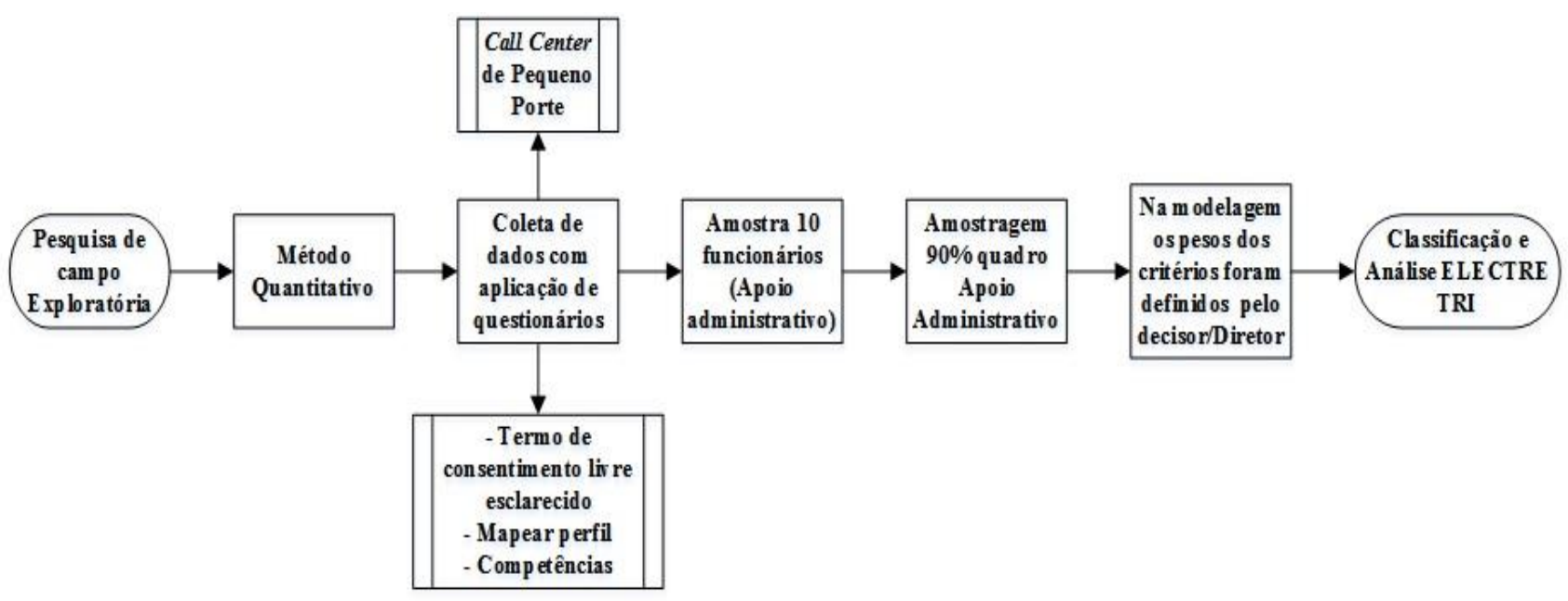

Fonte: Elaborado pelo autor (2014).

A escolha do método depende de vários fatores que devem ser considerados. De acordo com Almeida, A.T. (2013), devem ser observadas as características do problema analisado, a estrutura de preferência do decisor e a problemática. Um fator que também deve ser observado são as informações intercritérios (Sobral, 2013). O aspecto de compensação sugere uma quantidade que contrabalanceie a desvantagem de um critério em relação à vantagem de outro. Após análise do problema, observou-se que o ELECTRE TRI reúne todos os fatores necessários para a correta aplicação no contexto de estudo. 


\section{MODELAGEM E ANÁLISES DOS RESULTADOS}

O ELECTRE TRI possibilitou analisar e classificar o grau de competência dos profissionais que atuam no apoio administrativo de um Call Center. Por meio da avaliação por competências, foi estabelecida a criação de múltiplos critérios, possibilitando, assim, identificar e classificar as competências predominantes nos profissionais. As etapas para utilização do método ELECTRE TRI ocorreram da seguinte maneira:

a) caracterizar o problema e identificar as alternativas de soluções possíveis;

b) especificar os critérios: com base na avaliação por competências, definir os critérios e subcritérios, baseados no eixo das competências: Conhecimento, Habilidade e Atitude;

c) criar uma escala de julgamento para os pesos: a cada critério, foram atribuídos pesos de acordo com o grau de importância da competência com a atividade exercida pelos profissionais administrativos;

d) especificar uma escala de julgamento das alternativas para cada critério;

e) estabelecer as classes de equivalência (desempenho), utilizadas como padrão para a classificação das alternativas analisadas;

f) identificar as classes de equivalência: estabelecer para cada critério os limiares de preferência $(p)$ indiferença $(q)$ e o veto $(v)$;

g) executar o algoritmo de classificação do ELECTRE TRI;

Tabela 2 - Critérios e pesos adotados na modelagem.

\begin{tabular}{|c|c|c|}
\hline EIXOS & ABRANGÊNCIA & PESOS \\
\hline \multirow{3}{*}{ CONHECIMENTO } & 1.1 Recebe regularmente capacitação. & 0.07 \\
\hline & $\begin{array}{l}\text { 1.2 Sente-se preparado para novas oportunidades dentro da } \\
\text { empresa. }\end{array}$ & 0.07 \\
\hline & $\begin{array}{l}1.3 \text { Reconhece os problemas que surgem na execução de suas } \\
\text { rotinas administrativas. }\end{array}$ & 0.07 \\
\hline \multirow{3}{*}{ HABILIDADE } & 1.4 Sabe trabalhar em equipe. & 0.12 \\
\hline & $\begin{array}{l}1.5 \text { Possui autonomia para resolver os problemas que surgem } \\
\text { no cotidiano. }\end{array}$ & 0.10 \\
\hline & 1.6 Capacidade analítica na rotina laboral. & 0.15 \\
\hline \multirow{3}{*}{ ATITUDE } & 1.7 Age com ética nas relações profissionais no trabalho. & 0.15 \\
\hline & 1.8 Geralmente consegue ser proativo. & 0.12 \\
\hline & 1.9 Geralmente consegue concluir suas atividades. & 0.15 \\
\hline
\end{tabular}

Fonte: Dados da pesquisa (2014).

Revista de Gestão e Secretariado - GeSec, São Paulo, v. 5, n. 3, p 01-27, set./dez. 2014. 
No eixo Conhecimento, foram atribuídos pesos 0.07 por considerar que, para a atividade de apoio administrativo, a capacitação e o reconhecimento dos problemas que surgem no cotidiano apresentam um grau de destaque na execução de suas atividades.

Nos critérios relativos à competência Habilidade, foram considerados os pesos $0.12,0.10 \mathrm{e}$ 0.15. Destacando-se com peso 0.12 saber trabalhar em equipe (critério 1.4), peso 0.10 para a autonomia para solução de problemas (critério 1.5), e a capacidade analítica por ser uma habilidade essencial (critério 1.6) recebeu peso mais significativo 0,15, pela importância desta habilidade na condução de processos empresariais, na qual a capacidade de concentração, interpretação e diagnóstico é imprescindível nas rotinas administrativas.

Os critérios relacionados à Atitude receberam pesos mais significativos pela compreensão de que para esta atividade laboral é uma das competências mais relevantes no ambiente de trabalho, pois está associada aos aspectos comportamentais, ou seja, ao querer fazer. Dessa forma, foi atribuído peso 0.15 para os critérios relacionados ao agir com ética nas relações profissionais, pois nesta atividade o sigilo das informações e a honestidade devem ser princípios intrinsecamente arraigados no profissional (critério 1.7) e para a capacidade de concluir e entregar as demandas que lhes são apresentadas (critério 1.9), uma vez que este profissional tem prazos para a entrega de suas rotinas administrativas.

Através do ELECTRE TRI, foi possível trabalhar as particularidades de cada critério, como crescente ou decrescente. Todos os critérios foram tratados como crescentes, os profissionais atribuíram um grau de domínio de acordo com suas vivências no trabalho, conforme escala de julgamento listada na Tabela 3.

Tabela 3 - Escala de julgamento para os critérios de avaliação por competência.

\begin{tabular}{|c|c|}
\hline GRAU DE DOMÍNIO & PARECER \\
\hline 1 & RUIM \\
\hline 2 & RAZOÁVEL \\
\hline 3 & BOM \\
\hline 4 & EXCELENTE \\
\hline
\end{tabular}

Fonte: Dados da pesquisa (2014).

O método ELECTRE TRI lida com situações envolvendo critério verdadeiro. Esse método considera pseudocritério, usando limiares de indiferença e preferência (Almeida A. T., 2013). Cada profissional que respondeu ao questionário foi considerado como uma alternativa, e os critérios e os subcritérios fundamentados através da avaliação por competência. Na modelagem do ELECTRE TRI, para todos os critérios foram utilizados os seguintes limiares (Tabela 4):

Revista de Gestão e Secretariado - GeSec, São Paulo, v. 5, n. 3, p 01-27, set./dez. 2014. 
Tabela 4 - Parametrização do ELECTRE TRI

\begin{tabular}{|c|c|c|c|}
\hline Limiar de Indiferença & Limiar de Preferência & Veto & Nível de Corte \\
\hline 0 & 3 & 0 & 0.65 \\
\hline
\end{tabular}

Fonte: Dados da pesquisa (2014).

Para avaliar o grau de competência, foram criadas quatro classes ou categorias, denominadas conforme Tabela 5.

Tabela 5 - Descrição das categorias.

\begin{tabular}{|l|l|}
\hline \multicolumn{1}{|c|}{ CLASSES } & \multicolumn{1}{|c|}{ GRAU DE COMPETÊNCIA } \\
\hline CLASSE 1 & ELEVADO \\
\hline CLASSE 2 & BOM \\
\hline CLASSE 3 & RAZOÁVEL \\
\hline CLASSE 4 & RUIM \\
\hline
\end{tabular}

Fonte: Dados da pesquisa (2014).

Os limites de categoria tornam a modelagem mais ou menos rígida à classificação das alternativas (Sobral, 2013). Para cada competência e ou critérios, foram estabelecidos os limites de categoria, de maneira uniforme para todos os critérios, conforme demonstra a Tabela 6.

Tabela 6 - Limites de Categoria e perfis de referência.

\begin{tabular}{|c|c|}
\hline PERFIS & $\begin{array}{l}\text { LIMITES DE } \\
\text { CATEGORIA }\end{array}$ \\
\hline$b_{1}$ & 0.50 \\
\hline$b_{2}$ & 1.50 \\
\hline$b_{3}$ & 2.50 \\
\hline
\end{tabular}

Fonte: Dados da pesquisa (2014).

Existem dois procedimentos de classificação: o pessimista e o otimista. A regra do procedimento de exploração serve para analisar de que forma uma alternativa " $a$ " é comparada com os limites padrão determinados para a classe na qual a opção “ $a$ ” deve ser enquadrada (Lima et al., 2007).

O procedimento pessimista ou conjuntivo é efetuado da seguinte maneira: Comparar a sucessivamente com $b_{i}$, para $i=p, p-1, \ldots, 0$; e que $b_{h}$ seja o primeiro limite padrão tal que $a S b_{h}$ classificando a para a classe $C_{h+1}\left(a \rightarrow . C_{h+1}\right)$. Se $b_{h-1}$ e $b_{h}$ denotam o limite superior e inferior da

Revista de Gestão e Secretariado - GeSec, São Paulo, v. 5, n. 3, p 01-27, set./dez. 2014. 
classe $C_{h}$, então o procedimento pessimista classifica a alternativa " $a$ " para a classe mais alta, de tal forma que subordine $b_{h-1}$, isto é $a S b_{h-1}$. Enquanto que no procedimento otimista ou disjuntivo compara a com $b_{i}, i=1,2, \ldots, p$; que $b_{h}$ seja o primeiro limite padrão tal que $b_{h}>a$, classificando a na classe $C_{h}\left(a \rightarrow\right.$. $\left.C_{h}\right)$, ou seja, classifica $a$ para a classe mais baixa $C_{h}$ para a qual o limite superior é $b_{h}$ é preferível a $a, i$. é $b_{h}>a$ (Lima et al., 2007).

Sendo a fundamentação dos dois procedimentos diferentes, é possível que uma mesma alternativa obtenha classificação oposta e cabe ao decisor escolher qual classificação será adotada (Lima et al., 2007). Na modelagem, foi realizada análise de sensibilidade nos dois procedimentos e apenas para $50 \%$ das alternativas houve resultado de classificação diferente. Na versão otimista, todas as alternativas foram alocadas na classe 1 com elevada competência, enquanto que na versão pessimista, as alternativas $\mathrm{A}_{1}, \mathrm{~A}_{2}, \mathrm{~A}_{4}, \mathrm{~A}_{7}$ e $\mathrm{A}_{9}$ foram classificadas na classe 4 com baixo desempenho. A alteração de dados indica que muitas alternativas ficaram na fronteira entre as classes. A classificação final adotada foi a gerada pelo procedimento pessimista, conforme demonstra a Tabela 7.

Tabela 7 - Alocação final das classes.

\begin{tabular}{|c|c|c|c|}
\hline \multicolumn{4}{|c|}{ CLASSIFICAÇÃO ELECTRE TRI } \\
\hline ELEVADO & BOM & RAZOÁVEL & BAIXO \\
\hline $\mathbf{A}_{3}$ & - & - & $\mathrm{A}_{1}$ \\
\hline $\mathbf{A}_{5}$ & - & - & $\mathrm{A}_{2}$ \\
\hline $\mathbf{A}_{6}$ & - & - & $\mathrm{A}_{4}$ \\
\hline $\mathbf{A}_{\mathbf{8}}$ & - & - & $\mathrm{A}_{7}$ \\
\hline $\mathbf{A}_{\mathbf{1 0}}$ & - & - & $\mathrm{A}_{9}$ \\
\hline
\end{tabular}

Fonte: Dados da pesquisa (2014).

A classificação final dos profissionais que atuam na área administrativa de um Call Center indica que a empresa tem problemas quanto à gestão de pessoas, pois $50 \%$ dos profissionais foram classificados com nível de competência baixo. Em contrapartida, 50\% foram classificados com elevada competência. O baixo desempenho de $50 \%$ dos profissionais se justifica pelo grau de complexidade processual existente na atividade, quando se compara com o tempo de atividade desses profissionais. Este resultado é confirmado pela análise, demonstrando que cerca de $30 \%$ destes profissionais têm apenas de um a seis meses na função, $40 \%$ têm de um a dois anos e somente $20 \%$ têm acima de quatro anos na função.

Revista de Gestão e Secretariado - GeSec, São Paulo, v. 5, n. 3, p 01-27, set./dez. 2014. 
O ELECTRE TRI apresentou aderência aos resultados, tomando como exemplo as alternativas $\mathrm{A}_{10}$ e $\mathrm{A}_{3}$ que responderam excelente para a maioria das competências e foram alocadas na classe 1, com nível de competência elevado.

É notória a dificuldade de um decisor em analisar, ao mesmo tempo, múltiplos critérios e múltiplas alternativas. $\mathrm{Na}$ avaliação de competências, existem ao menos três critérios (Conhecimento, Habilidade e Atitude), que devem ser eixos de julgamento das alternativas (que neste caso são os funcionários). Ao adicionar mais critérios na análise, o julgamento fica ainda mais complexo. Neste contexto, o ELECTRE TRI permitiu uma análise de forma mais simplificada, sem que necessariamente sacrificasse a acuidade da informação. Após a definição dos parâmetros do método, foi possível efetuar a análise de todos os funcionários, bem como sua alocação em classes ordenadas.

Como forma de analisar qual seria o impacto do erro na elicitação de pesos sobre os resultados, efetuamos um acréscimo de $30 \%$ nos pesos de um grupo, seguindo pela redução proporcional dos demais. Em todas as simulações não existiram alternativas ocupando as classes intermediárias (Bom e Razoável). Além disso, em todas as análises de sensibilidade, a mudança de categorias permaneceu abaixo de 10\%. Com estas informações, é possível assegurar que pequenos erros de elicitação dos pesos não serão suficientes para interferir de forma significativa nos resultados finais da classificação.

A adição do apoio multicritério, à avaliação por competências, se traduz como uma nova possibilidade para ambos os campos científicos e na modelagem apresentada ofereceu resultados que estavam coerentes com a estrutura de preferência do decisor.

\section{CONSIDERAÇÕES FINAIS}

O presente estudo se propôs a analisar e classificar os profissionais que atuam no apoio administrativo de um Call Center, com base na avaliação por competências, considerando o CHA (Conhecimento, Habilidade e Atitude). O conhecimento está relacionado ao saber; a habilidade, à técnica; e a atitude, ao querer fazer. Além da pesquisa de campo de caráter exploratório, também foi realizada uma breve revisão de literatura sobre avaliação por competências: as competências do profissional de Secretariado, a evolução do setor de Call Center, o Apoio Multicritério à Decisão e

Revista de Gestão e Secretariado - GeSec, São Paulo, v. 5, n. 3, p 01-27, set./dez. 2014. 
o método ELECTRE TRI.

O Apoio Multicritério à Decisão, através do ELECTRE TRI, ofereceu uma metodologia adequada, pois condensou todos os critérios criados baseados na gestão por competência e fez um julgamento de cada funcionário à luz de cada competência: Conhecimento, Habilidade e Atitude. O ELECTRE TRI possibilitou a classificação dos profissionais a partir de avaliações simultâneas, considerando ao mesmo tempo os múltiplos critérios estabelecidos.

O resultado final constatou que metade dos funcionários foi classificada com nível de competência baixo. Entretanto, os outros 50\%, com competência elevada. Este resultado poderia ser justificado pelo grau de complexidade processual existente na atividade, quando relacionado com tempo de atividade dos profissionais. Os dados confirmam isto, uma vez que cerca de $30 \%$ destes profissionais têm apenas de um a seis meses na função, $40 \%$ têm de um a dois anos e somente $20 \%$ têm acima de quatro anos na função. Algumas competências, como conhecimento e habilidade, são adquiridas também com as vivências empíricas, o que produz o conhecimento tácito.

O elevado desempenho demonstrado por $50 \%$ dos profissionais pode ser justificado pela formação acadêmica deles; $50 \%$ dos quais possuem nível superior completo e 30\% superior incompleto. A formação é um elemento importante, pois o conhecimento que o indivíduo adquire o acompanha na vida profissional e interfere no desempenho de suas competências.

Ainda, o resultado constata que existe um paradoxo, no qual 50\% dos profissionais foram classificados com competência elevada e 50\% com baixo desempenho, demonstrando que ou os profissionais são muito preparados para a função, ou estão ainda no início da escala de aprendizado, também justificado pelo pouco tempo que atuam na função.

O ELECTRE TRI apresentou aderência aos resultados, tomando como exemplo as alternativas $\mathrm{A}_{10}$ e $\mathrm{A}_{3}$ que responderam excelente para a maioria das competências e foram alocadas na classe 1 com nível de competência elevado. A modelagem condensou todos os critérios com julgamento de cada funcionário, e a partir da classificação final das pessoas permitiu ao decisor avaliar e analisar as competências dos profissionais, contemplando múltiplos critérios estabelecidos, auxiliando na tomada de decisão.

Como se trata de uma equipe de apoio administrativo que lida com procedimentos burocráticos e sigilosos, de alta responsabilidade gerencial, este resultado sugere que a alta direção atue com programas de desenvolvimento destes profissionais, com treinamento envolvendo capacitação técnica e procedimental, principalmente dos mais jovens na atividade, incentivando a busca pela formação acadêmica, visto que $20 \%$ deles não possuem a formação necessária para a execução da atividade de assessor administrativo.

Revista de Gestão e Secretariado - GeSec, São Paulo, v. 5, n. 3, p 01-27, set./dez. 2014. 
Para realizar o assessoramento dos gestores, os profissionais precisam ter as competências desenvolvidas baseadas em melhores práticas de gestão de processos, pessoas e práticas de Secretariado. Neste contexto, a modelagem surge como uma importante ferramenta de avaliação, fornecendo ao decisor suporte no mapeamento das competências. Auxilia, também, nos processos de demissão, contratação e treinamento.

Dessa maneira, é possível evidenciar as possibilidades de atuação do secretário executivo em qualquer setor de uma organização social, por meio da função de assessor, que lhe permite dar assistência aos gestores nos mais diversos níveis hierárquicos, em virtude da sua polivalência.

Como já mencionado, a presente modelagem apresenta um novo marco para a gestão de competências, permitindo sua análise, por meio de uma técnica simplificada e estruturada. A definição dos parâmetros do ELECTRE TRI ainda pode ser considerada como complexa, porém recomenda-se a realização de análises de sensibilidade, de forma a verificar a robustez dos resultados. Na modelagem apresentada, efetuamos as análises, o que permitiu assegurar que os resultados não variavam de forma significativa em função de erros de elicitação dos pesos.

Como sugestão para trabalhos futuros, é necessário analisar as competências requeridas para o cargo de assessor administrativo à luz das práticas secretariais, comparando as competências dos profissionais, segundo sua própria ótica de julgamento. Sugerimos, além disso, a aplicação de novos métodos para decisão em grupo, em contextos onde existam mais de um decisor.

\section{REFERÊNCIAS}

ABT. (17 de abril de 2014). Associação Brasileira de Telesserviços - ABT. Fonte: Associação Brasileira de Telesserviços - ABT:http://www.abt.org.br/codigo_etica.asp?banner=ABT

Adelino, F. J., \& Silva, M. A. (2012). A tecnologia da informação como agente de mudança no perfil do profissional de Secretariado. Revista de Gestão e Secretariado - GeSec, 05-23.

Almeida, A. T. (2013). Processo de decisão nas organizações: construindo modelos de decisão multicritério. São Paulo: Atlas.

Almeida, W. G., Rogel, G. T., \& Shimoura, A. d. (2010). Mudanças de Paradigma na gestão do profissional de Secretariado . Revista de Gestão e Secretariado - GeSec , 46-68.

Revista de Gestão e Secretariado - GeSec, São Paulo, v. 5, n. 3, p 01-27, set./dez. 2014. 
Araujo, L. C., \& Garcia, A. A. (2010). Gestão de pessoas . São Paulo: Atlas.

Bahry, C. P., \& Tolfo, S. d. (2004). A gestão de competências e a obtenção de vantagem competitiva sustentável em organizações bancárias. Revista de Administração Makenzie, pp. 3754.

Barros, C. d., Silva, J. S., Lima, G. A., \& Brito, D. G. (2013). As competências gerenciais desenvolvidas pelos secretários executivos. Revista de Gestão e Secretariado - GeSec, 25-47.

Boyatzis, R. E. (1992). The core competent management: a model for effective performance. New York.

CallCenter.inf.br. (2014). CallCenter.inf.br. Recuperado em 8 de abril, 2014, de Callcenter.inf.br: http://ranking.callcenter.inf.br/resumo/

CIP (Novembro de 2013). Tradição em alta. Consumidor Moderno, 186, 24-32.

Durand, T. (2000). L’Alchimie de la compétence. Revue Française de Gestion .

Fleury, A., \& Fleury, M. T. (2011). Competência e aprendizagem organizacional . In: A. Fleury \& M. T. Fleury, Estratégias empresariais e formação de competências (pp. 26-40). São Paulo: Atlas.

Fontanella, R. (2011). Os tipos comportamentais dos executivos e a postura do profissional de Secretariado. Revista de Gestão e Secretariado, 79-104.

Gil, A. C. (2010). Como elaborar projetos de pesquisa. São Paulo: Atlas.

Golfetto, F., \& Gibbert, M. (2006). Marketing competencies and the sources of customer value in business markets. Industrial Marketing Management, 904-912.

Gomes, L. F., Araya, M. C., \& Carignano, C. (2004). Tomada de decisões em cenários complexos: introdução aos métodos discretos de apoio multicritério a decisão (1a ed.). São Paulo: Thomson

Jamil, G. L., \& Silva, F. B. (2005). Call Center e telemarketing. Rio de Janeiro: Axcel Books do Brasil.

Leal, F. G. \& Fiates, G. G. (2013). Competências dos secretários executivos de uma universidade pública federal: uma análise a partir da perspectiva dos gestores. Revista de Gestão e Secretariado - GeSec, 30-57.

Revista de Gestão e Secretariado - GeSec, São Paulo, v. 5, n. 3, p 01-27, set./dez. 2014. 
Lima, J. E., Neves, C. L., Santos, R. M., Vergara, F. E., Souza, M. A., \& Neto, O. M. (2007). Desenvolvimento de aplicativo para uso do método muticritério ELECTRE TRI . I Simpósio de Recursos hídricos do Norte e Centr-oeste, ABRH, 1-20.

Lima, T. F., \& Cantarotti, A. (2010). A formação e a construção de competências para a atuação do profissional de Secretariado Executivo - um estudo de caso em uma empresa júnior. Revista de Gestão e Secretariado, 94-122.

Madruga, R. (2009a). Código de defesa do consumidor e Código de ética . In: R. Madruga, Call Centers de alta performance (pp. 72-73). Recife: Atlas.

Madruga, R. (2009b). Gestão moderna de Call Center e telemarketing (2a ed.). São Paulo: Atlas.

Marconi, M. d., \& Lakatos, E. M. (2011). Metodologia científica (6a ed., vol. 1). (1. b. s.a, Ed.) São Paulo: Atlas.

Mascarenhas, M. H., Sepulveda, F. A., \& D’Assumpção, E. S. (2011). Sistema de Gestão Integrado: a atuação do secretário executivo . Revista de Gestão e Secretariado - GeSec, 177-192.

Maximiano, A. C. (2012). Teoria geral da administração: da revolução urbana à revolução digital (7a ed.). São Paulo: Atlas.

McClelland, D. C. (1973). Testing for competence rather than for "intelligence". American Psychologist, 1-13.

McLagan, P. A. (1997). Competencies: the next generation. Training and development, 40-47.

Moreira, K. D., \& Olivo, L. C. (2012). O profissional de secretariado executivo como mediador de conflitos de conflitos. Revista de Gestão e Secretariado, 30-53.

Mousseau, V., \& Slowinski, R. (1998). Inferring an ELECTRE TRI model from assignment examples. Journal of Global Optimization, 12, 157-174.

Nunes, S. C., \& Barbosa, A. C. (2009). Formação baseada em competências? Um estudo em cursos de graduação em administração. RAM - Revista de Administração Mackenzie, 28-52.

Oliveira, D. d. (2011). Sistema, organização e métodos. São Paulo: Atlas.

Revista de Gestão e Secretariado - GeSec, São Paulo, v. 5, n. 3, p 01-27, set./dez. 2014. 
Pereira, K. A., \& Silva, M. R. (2014). A atuação do secretário executivo no terceiro setor na cidade de Aracaju. Revista de Gestão e Secretariado - GeSec, 104-130.

Planalto.gov.br. (17 de abril de 2014). http://www.planalto.gov.br/ccivil_03/_ato20072010/2008/decreto/d6523.htm. Fonte: http://www.planalto.gov.br: http://www.planalto.gov.br/ccivil_03/_ato2007-2010/2008/decreto/d6523.htm

Planalto.gov.br. (19 de junho de 2014). www.planalto.gov.br. Fonte: www.planalto.gov.br:http://www.planalto.gov.br/ccivil_03/Leis/L7377consol.htm

Portal.mte.gov.br/. (17 de abril de http://portal.mte.gov.br/data/files/FF8080812BE914E6012BEFBAD7064803/nr_17.pdf. Fonte: portal.mte.gov.br:http://portal.mte.gov.br/data/files/FF8080812BE914E6012BEFBAD7064803/n r_17.pdf

Prahalad, C., \& Hamel, G. (1990). The core competence of the corporation. Harvard Business Review, 79-91.

Ricci, M. G., \& Rachid, A. (2013). Relações de trabalho no serviço de teleatendimento. Gestão \& Produção, 192-203.

Roy, B. (1990). Decision-aid and decision-makingDecision-aid and decision-making. Elsevier Science publishers, 324-331.

Roy, B. (1996). Multicriteria methodology for decision aiding. London: Kluwer Academic Publishers.

Roy, B., \& Vanderpooten, D. (1996). The European School of MCDA: emergence, basic features and current works. Journal of Multi-Criteria Decision Analysis, 5, 22-38.

Russo, G. (2010). Diagnóstico da cultura organizacional: O impacto dos valores organizacionais no desempenho das terceirizações. São Paulo: Campus .

Sabino, R. F. \& Marchelli, P. S. (2009). O debate teórico-metodológico no campo do secretariado: pluralismos e singularidades. Cadernos Ebape. BR, 608-621.

Scolari, C., Costa, S. G., \& Mazzilli, C. (2009). Prazer e sofrimento entre os trabalhadores de Call Center. Psicologia USP, 555-576.

Sobral, M. F. (2013). Uso da modelagem multicritério de apoio ao decisor na alocação de Revista de Gestão e Secretariado - GeSec, São Paulo, v. 5, n. 3, p 01-27, set./dez. 2014. 
produtos na matriz mercadológica do ciclo de vida dos produtos. Exacta São Paulo, 11, pp. 173186.

Szajubok, N. K., Mota, C. M., \& Almeida, A. T. (Setembro a dezembro de 2006). Uso do método multicritério ELECTRE TRI para classificação de estoques na construção civil. Pesquisa Operacional , 26(3), 625-648.

Terra, E. F., \& Machado, F. H. (2011). O Secretário Executivo e a flexibilidade comportamental no trabalho . Revista de Gestão e Secretariado - GeSec, 105-120.

Todorov, M. do C., Kniess, C. T., \& Chaves, M. S. (2013). As competências do profissional de secretariado na implantação de projetos sustentáveis. Revista de Gestão e Secretariado - GeSec, 189-209.

Yu.W. (1992). ELECTRE TRI: aspects méthodologiques et guide d'utilisation. Paris : Dauphine Université Paris (Document du Lamsade, n.74).

Zarifian, P. (2012). Objetivo Competência: por uma nova lógica. São Paulo: Atlas.

Zopounidis, C., \& Doumpos, M. (2002). Multicriteria classification and sorting methods: A literature review. European Journal of Operational Research, 138, 229-246.

Revista de Gestão e Secretariado - GeSec, São Paulo, v. 5, n. 3, p 01-27, set./dez. 2014. 